\title{
Inoculação de Curvularia eragrostidis em inhame (Dioscorea alata) cv. São Tomé
}

\author{
Rodrigo Pereira Leite ${ }^{1}$, Luciana Cordeiro do Nascimento ${ }^{1}$, Mônica Danielly de Mello Oliveira ${ }^{1}$
}

\author{
${ }^{(1)}$ Universidade Federal da Paraíba, Centro de Ciências Agrárias, Programa de Pós-Graduação em Agronomia, Campus II, Rod. PB 079 km 12 s/n \\ Campus Universitário, CEP 58397-000 Areia, PB, Brasil. \\ Autor para correspondência: Mônica Danielly de Mello Oliveira (monicadmportella@gmail.com) \\ Data de chegada: 22/06/2017. Aceito para publicação em: 05/11/2017.
}

$10.1590 / 0100-5405 / 181626$

\section{RESUMO}

Leite, R.P.; Nascimento, L.C.; Oliveira, M.D.M. Inoculação de Curvularia eragrostidis em inhame (Dioscorea alata) cv. São Tomé. Summa Phytopathologica, v.44, n.3, p.281-282, 2018.

Objetivou-se selecionar o método de inoculação de Curvularia eragrostidis em mudas de inhame (Dioscorea alata) cv. São Tomé para a determinação da infecção e do período de latência. O isolado de C. eragrostidis foi obtido a partir de folhas de inhame com sintomas da doença. Plantas com 45 dias de idade, cultivadas em casa de vegetação, foram inoculadas com o patógeno da seguinte forma: T1 - Suspensão de esporos $\left(1 \times 10^{5}\right.$ conídios $\left.\mathrm{mL}^{-1}\right)$; T2 - Discos de colônia de $10 \mathrm{~mm}$ fixados com fita adesiva (dois na face abaxial e um na face adaxial);
T3 - Pincelamento de esporos; T4 - Algodão umedecido na suspensão de inóculo; T5 - testemunha (plantas borrifadas com água destilada e esterilizada). Após 72 $\mathrm{h}$ da inoculação, a incidência da doença foi avaliada diariamente e a severidade avaliada ao $15^{\circ}$ dia. Os resultados obtidos revelaram que a pulverização de suspensão de esporos foi mais eficiente na inoculação de C. eragrostidis em mudas de inhame, ocasionando o aparecimento dos primeiros sintomas a partir do terceiro dia após a inoculação.

Palavras-chave: queima das folhas, incidência, severidade.

\section{ABSTRACT}

Leite, R.P.; Nascimento, L.C.; Oliveira, M.D.M. Inoculation of Curvularia eragrostidis in yam plants (Dioscorea alata) cv. São Tomé. Summa Phytopathologica, v.44, n.3, p.281-282, 2018.

The aim of this study was to select the method of C. eragrostidis inoculation in yam seedlings (Dioscorea alata) cv. São Tomé to determine the infection and the latency period. The isolate of $C$. eragrostidis was obtained from yam leaves showing symptoms of the disease. Plants aged 45 days old, cultivated in a greenhouse, were inoculated with the pathogen, as follows: $\mathrm{T} 1-$ Spore suspension $\left(1 \times 10\right.$ conidia $\left.\mathrm{mL}^{-1}\right)$; $\mathrm{T} 2-$ Colonial disks of $10 \mathrm{~mm}$ fixed with adhesive tape (two on the abaxial surface and one on the adaxial surface); T3 - Brushing of spores; T4 - Cotton soaked in the inoculum suspension; T5 - Control (plants sprayed with sterile distilled water). After $72 \mathrm{~h}$ of inoculation, the disease incidence was daily evaluated and the severity was assessed on the $15^{\text {th }}$ day. The obtained results revealed that the spore suspension spraying method was more efficient for C. eragrostidis inoculation in yam seedlings, causing the first symptoms to appear from the third day after inoculation.

Keywords: leaf blight, incidence, severity.

O cultivo do inhame (Dioscorea $\mathrm{sp}$.) vem crescendo nos últimos anos e, no Brasil, a cultura concentra-se principalmente na região Nordeste, onde é cultivado utilizando-se mão de obra familiar e baixos níveis tecnológicos, que não tem permitido alcançar produtividade satisfatória (2).

As limitações de produtividade estão diretamente relacionadas à ocorrência de doenças, dentre as quais a queima das folhas, causada pelo fungo Curvularia eragrostidis (Henn.) Meyer [teleomorfo Cochliobolus eragrostidis Tsuda \& Ueyama], considerada a principal doença foliar dessa cultura (5), cujos sintomas caracterizam-se por manchas foliares necróticas, de coloração marrom-escura, circundadas por um halo amarelo (4).

O desenvolvimento de metodologias de inoculação visando uma avaliação precoce da resistência de materiais vegetais a patógenos consiste numa importante etapa na seleção de genótipos superiores em programas de melhoramento (1). Dessa forma estudos com métodos de inoculação, são importantes para o conhecimento do patossistema C. eragrostidis x Dioscorea spp. Nesse sentido, o presente trabalho teve como objetivo avaliar métodos de inoculação de $C$. eragrostidis em mudas de inhame.
Os experimentos foram conduzidos em casa de vegetação e no Laboratório de Fitopatologia, Centro de Ciências Agrárias da Universidade Federal da Paraíba - UFPB, Areia-PB. O isolado de $C$. eragrostidis foi obtido a partir de folhas de inhame com sintomas da doença, coletadas em áreas de produção comercial no município de Areia-PB e seu isolamento constou da desinfestação superficial de fragmentos das folhas com etanol $70 \%$ por 30 segundos, hipoclorito a $1 \%$ por 1 minuto, e duas lavagens com água destilada esterilizada $(\mathrm{ADE})$ e, acondicionados em placas de Petri contendo meio BDA e acondicionadas a $25 \pm 2^{\circ} \mathrm{C}$, por sete dias sob alternância luminosa de $12 \mathrm{~h}$. A identificação do fungo foi feita através de literatura especializada (6), com o auxílio de microscópio ótico As plântulas inoculadas com o patógeno tinham 45 dias de idade, cultivadas em vasos, em casa de vegetação. A suspensão de conídios foi preparada a partir de colônias fúngicas crescidas em BDA, conforme descrito anteriormente, e ajustada para $5 \times 10^{5}$ conídios. $\mathrm{mL}^{-1}$. O delineamento experimental foi DIC, com cinco tratamentos de cinco repetições. As inoculações de $C$. eragrostidis foram dispostas em T1 - Suspensão de esporos $\left(1 \times 10^{5}\right.$ conídios. $\left.\mathrm{mL}^{-1}\right)$; T2 - Discos de colônia de $10 \mathrm{~mm}$ fixados com fita adesiva (dois na face abaxial e um na face adaxial); 
Tabela 1. Incidência e severidade dos sintomas em função dos diferentes métodos de inoculação de Curvularia eragrostidis em folhas de inhame. Areia, PB 2011.

\begin{tabular}{|c|c|c|c|c|c|c|c|c|c|c|c|c|c|c|}
\hline \multirow{3}{*}{ Métodos } & \multicolumn{13}{|c|}{ Incidência (\%) } & \multirow[t]{2}{*}{ Severidade (\%) } \\
\hline & \multicolumn{13}{|c|}{ Dias após a inoculação } & \\
\hline & 3 & 4 & 5 & 6 & 7 & 8 & 9 & 10 & 11 & 12 & 13 & 14 & 15 & \\
\hline SE & $24 a^{*}$ & $28 \mathrm{a}$ & $34 \mathrm{a}$ & $44 a$ & $50 \mathrm{a}$ & $56 \mathrm{a}$ & $61 \mathrm{a}$ & $71 \mathrm{a}$ & $80 \mathrm{a}$ & $86 \mathrm{a}$ & $90 \mathrm{a}$ & $93 a$ & $93 a$ & $59,6 \mathrm{a}$ \\
\hline DC & $0 \mathrm{~b}$ & $0 b$ & $20 b$ & $25 \mathrm{bc}$ & $30 b$ & $36 b$ & $42 b$ & $51 b$ & $56 b$ & $63 b$ & $67 b$ & $74 b$ & $74 b$ & $50,0 \mathrm{~b}$ \\
\hline PE & $0 \mathrm{~b}$ & $0 \mathrm{~b}$ & $22 b$ & $29 b$ & $33 b$ & $40 b$ & $47 b$ & $53 b$ & $59 b$ & $67 b$ & $72 b$ & $76 b$ & $76 b$ & $49,3 \mathrm{~b}$ \\
\hline $\mathbf{A U}$ & $0 \mathrm{~b}$ & $0 \mathrm{~b}$ & $0 \mathrm{c}$ & $17 \mathrm{c}$ & $22 c$ & $27 \mathrm{c}$ & $32 c$ & $38 \mathrm{c}$ & $44 c$ & $50 \mathrm{c}$ & $56 c$ & $60 c$ & $60 c$ & $30,0 \mathrm{c}$ \\
\hline TE & $0 \mathrm{~b}$ & $0 \mathrm{~b}$ & $0 \mathrm{c}$ & od & $0 \mathrm{~d}$ & od & $0 \mathrm{~d}$ & Od & Od & Od & $0 \mathrm{~d}$ & Od & $0 \mathrm{~d}$ & $00,0 \mathrm{~d}$ \\
\hline CV $(\%)$ & 51,0 & 35,7 & 23,3 & 18,7 & 14,6 & 11,5 & 11,6 & 9,8 & 9,5 & 8,1 & 8,1 & 6,6 & 6,6 & 3,6 \\
\hline
\end{tabular}

SE - Suspensão de esporos (1x10 conídios $\left.\mathrm{mL}^{-1}\right)$; DC - Discos de colônia de $10 \mathrm{~mm}$ fixados com fita adesiva (dois na face abaxial e um na face adaxial); PE Pincelamento de esporos; AU - Algodão umedecido na suspensão de inoculo; TE - testemunha (plantas borrifadas com ADE). CV - coeficiente de variação (\%). *Médias seguidas de mesma letra nas colunas não diferem entre si pelo teste de Tukey (5\%).

T3 - Pincelamento de esporos; T4 - Algodão umedecido na suspensão de inóculo; T5 - testemunha (plantas borrifadas com água destilada e esterilizada). Após as inoculações, as plântulas foram mantidas em casa de vegetação por 15 dias.

Para a análise da doença utilizou-se escala diagramática estabelecida para $C$. eragrostidis (3), com severidade variando de 0 a $32 \%$. A severidade de manchas foliares foi estimada ao $15^{\circ}$ dia após as inoculações e os dados foram submetidos à análise de variância e as médias foram comparadas pelo teste de Tukey $(\mathrm{P}=0,05)$. As avaliações de incidência foram realizadas diariamente, após $72 \mathrm{~h}$ da inoculação a partir do número de folhas afetadas.

Foram observadas diferenças significativas entre os métodos de inoculação, tanto para a incidência, quanto para a severidade avaliadas (Tabela 1). O método de suspensão de esporos proporcionou maior incidência quando comparado aos demais tratamentos. Aos 15 dias após a inoculação, o tratamento com suspensão de esporos apresentou $93 \%$ de incidência e 59,6\% de área foliar necrosada diferindo estatisticamente dos demais métodos.

A severidade permitiu identificar a eficiência do método em inocular C. eragrostidis em plantas de inhame e avaliar com maior precisão e rapidez a reação da resistência ou suscetibilidade de materiais vegetais em função da severidade do patógeno. Essa resposta consiste numa importante etapa na seleção de genótipos superiores em programas de melhoramento vegetal.

Os sintomas primários foram manchas necróticas de coloração marrom-escura, corroborando com Moura (4). Gomes et al. (1), estudaram diferentes métodos de inoculação de Phakopsora euvitis em videira "Isabel" e comprovaram que o método do pincelamento de esporos foi o mais eficiente na inoculação do fungo em mudas de videira, propiciando o aparecimento dos primeiros sintomas a partir do quinto dia após a inoculação e $100 \%$ de infecção após o $13^{\circ}$ dia. Tais resultados diferem dos obtidos nesse trabalho, onde a inoculação do C. eragrostidis pelo método do pincelamento de esporos apresentou baixa eficiência.

Neste trabalho, o método da pulverização de suspensão de esporos foi o método mais eficiente na inoculação de $C$. eragrostidis em plantas de inhame, ocasionando o aparecimento dos primeiros sintomas a partir do terceiro dia após a inoculação, podendo ser utilizado de forma eficiente em testes de patogenicidade em programas de melhoramento de plantas visando resistência no patossistema $C$. eragrostidis x $D$. alata.

\section{AGRADECIMENTOS}

A CAPES pela concessão das bolsas de pós-doutorado e mestrado.

\section{REFERÊNCIAS}

1. GOMES, E.C.S., NASCIMENTO, L.C., PEREZ, J.O., LEITE, R.P., SILVA, F.J.A.S. Métodos de inoculação de Phakopsora euvitis Ono em Vitis labrusca L. Ciência Rural, Santa Maria, v.40, n.4, p.983-985, 2010.

2. MENDES, R.A. Cultivando inhame ou Cará da Costa. Embrapa, Cruz das Almas, p.26, 2005.

3. MICHEREFF, S.J.; MAFFIA L.A.; NORONHA, M.A. Escala diagramática para avaliação da severidade da queima das folhas do inhame. Fitopatologia Brasileira, São Paulo, v.24, p.174-180, 2000.

4. MOURA, R.M. Doenças do inhame da Costa. In: KIMATI, H.; AMORIM, L.; BERGAMIN-FILHO, A.E; CAMARGO, L.E.A. (Ed.) Manual de Fitopatologia: doenças das plantas cultivadas, 2005, $4^{\text {a }}$ ed. Ceres: São Paulo. v. 2, p. 415- 419.

5. NORONHA, M.A. Intensidade da queima das folhas do inhame no Estado de Alagoas. Embrapa, Alagoas, p. 1-6, 2016.

6. SEIFERT, K.; GAMS, W. The genera of Hyphomycetes. CBS-KNAW Fungal Biodiversity Centre, Utrecht, 2011, p. 866. 